\title{
THE QUESTION OF ENERGY-EFFICIENT DESIGN OF THE AUTOMATED ELECTRIC DRIVE OF MULTI-ENGINE BELT CONVEYORS
}

\author{
Irina Semykina ${ }^{1 \mathrm{a}}$, Valery Zavyalov \\ ${ }^{1}$ National Research Tomsk Polytechnic University, 634050 Tomsk, Russia
}

\begin{abstract}
The article proposes a method for improving the energy efficiency of multi-motor variable frequency electric drives of trunk belt conveyors, based on the conveyor speed changing and controlling of the magnetic state of the motor. At conclusion, economic and energy effects of the implementation are estimated.
\end{abstract}

\section{Introduction}

Currently, the energy efficiency improvement is coming to the foreground. Energy saving, i.e. rationalization of energy production, distribution and utilization has become one of the important technical task. Because of about $60 \%$ of produced energy is consumed by electric drives of various applications the energy efficiency measures in the electric drive have a high effectiveness.

A special category of industrial applications with electric drive is mining machines for coalmines including equipment for coal transportation to the surface via the trunk belt conveyors. This conveyor operates in a changing load that is why its electric drive should provide the energy saving by choosing the rational operation mode of the conveyor or by reducing the losses in the electric drive.

The major economy reserves for belt conveyors are in the field of automatic electric drive with frequency convertor. It is simple and it has good control behaviors. Moreover, there are basic researches [1-4] that propose the control methods for automatic electric drives to optimize the energy consumption, but no one of methods contain specification for the belt conveyors.

To get this specification researches $[5,6]$ describe a scientific substantiation of increasing the belt conveyors energy efficiency by means the electric drive speed changing. The speed should ensure the continued belt conveyors performance at the constant motor load torque. It confirms by a joint research of German and Polish specialists [7] there the advantages of the conveyor speed controlling are evident on the main transport routes of the mine. For example in the Westfalen mine in Germany conveyor's four electric motors with total capacity of $320 \mathrm{~kW}$ have got $39 \%$ energy efficiency improving per ton by controlling of the conveyor speed.

However, the ability of the electric drive speed changing is not always available because of existing technological schemes of trunk belt conveyors. In this case, to get energy efficiency with variable frequency drive we need not only install the frequency converter, but also use the correctly

a Corresponding author : semykina@tpu.ru

This is an Open Access article distributed under the terms of the Creative Commons Attribution License 4.0, which permits unrestricted use, distribution, and reproduction in any medium, provided the original work is properly cited. 
selected and configured control system. Thus, the important criteria of the energy efficiency become a level of electric drive power losses.

\section{Experimental setup and study technique}

The study of conveyor electric drive effectiveness with different control system configurations was carried out on trunk belt conveyor, which operates at one of the Kuzbass mines. It contains three motors at a head drive and two motors at a halfway drive with capacity of $500 \mathrm{~kW}$ for each motor. Features of this trunk belt conveyor are a rigorous requirement of drives load leveling because of high conveyor length and a very high coefficient of power headroom accepted in design. Due to this, the average load of the conveyor motor is not more than $30 \%$ of the nominal. ABB Company frequency converters ACS 800 control electric motors of head and halfway drives. The frequency converters with direct torque control system support the required electromagnetic torque and the constant reference flux of motors and so provide the operation mode with the constant average conveyor speed. All frequency converters are connected to the overall automation system and give the monitoring data. This data from several working shifts was used to analyze the operation of the trunk belt conveyor electric drives.

The study technique consist of three stages. In the first one, the characteristics of the $500 \mathrm{~kW}$ MORLEY motor (Fig. 1) was analyzed. On basis of these characteristics, the dependence of the output motor power $P_{2}$, the consumed motor power $P_{1}$ and the electric power losses of motor $\Delta P$ on the motor load was calculated. After that, the dependence of $P_{1}$ and $\Delta P$ on the motor load was approximated by the curve of the first and third order respectively.

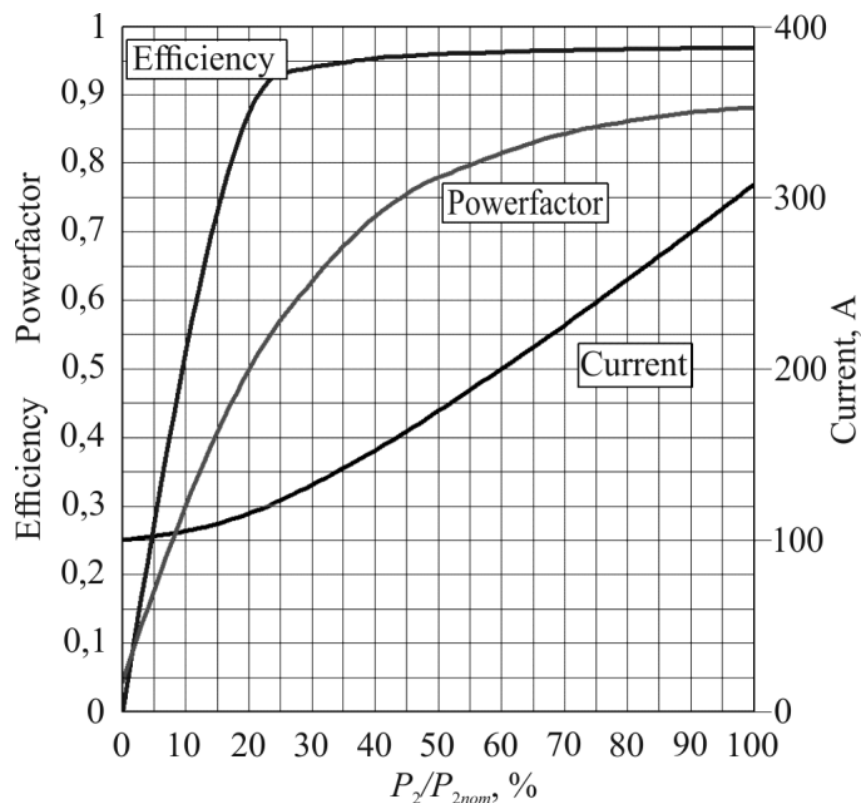

Figure 1. Characteristics of the $500 \mathrm{~kW}$ MORLEY motor

In the second stage, the monitoring data was processed. Monitoring data contain information on the speed, the electromagnetic torque, the stator current, the consumed power $P_{1 v f d}$ and the supply voltage of each motor. Initially, because of the motor speed by the monitoring data is below the nominal level, to keep the adequacy of the comparison with uncontrolled motors the following assumption was accepted. Increasing the conveyor speed, when dealing with uncontrolled electric drive, provides a smaller layer of transported cargo on the belt. The torque $M_{u c d}$ that produced by 
uncontrolled motor is less than the variable frequency motor torque $M_{v f d}$. The variable frequency motor speed $\omega_{v f d}$ is lower than the nominal synchronous speed $\omega_{u c d}$. This dependence is proportionate:

$$
M_{u c d}=M_{v f d} \frac{\omega_{v f d}}{\omega_{u c d}} .
$$

Inclusive of this assumption and the first stage approximation, the output power $P_{2 v f d}$, the motor load, the electric power losses $\Delta P_{v f d}$ depending on $M_{v f d}$ was calculated for each variable frequency drive. After that, the consumed power of uncontrolled motor $P_{1 u c d}$ was estimated and actual saving $S_{v f d}$ was calculate by the formula:

$$
S_{v f d}=\frac{P_{1 u c d}-P_{1 v f d}}{P_{1 u c d}} .
$$

The third stage contain estimation of energy efficiency by impact on the motor magnetic flux. In the frequency converters with $\mathrm{u} / \mathrm{f}$ control it may be achieved by variation of motor slip for a given operating mode by means of optimal stator voltage search algorithm based on [8]. For the frequency converters with vector control systems a special method for numerical search of optimal flux [9] may be applied. In ACS 800 frequency converters it is achieved by using the option «flux optimization». That is why for given electric drives of the trunk belt conveyor the «flux optimization» was analyzed to estimate potential saving $S_{\text {opt }}$.

It should be noted that the formula for determining the optimal motor magnetic flux does not specified by producers of ACS 800 . It is the ABB know-how. Therefore, the estimation of the saving by using the «flux optimization» was carry out approximately by the «region of saving». This term under the above analysis refers to the maximum and minimum boundaries of the economy and real $S_{\text {opt }}$ is located between them.

The first border of the «region of saving» was deterninad by a maximum voltage drop so that the critical motor torque exceeds the real motor torque by not more than $20 \%$. In this case, although the loss is the lowest such motor operation is unacceptable from a practical point of view.

The second border of the «region of saving» was formed by reduction of voltage that the minimum critical motor torque at the maximum voltage drop corresponds to starting torque of the motor. The remaining values of the voltage at intermediate values from the minimum load to the nominal load was formed by s-shaped characteristic.

\section{Experimental results}

The first result of the study is the analysis by time. It visualized the difference between the consumed power $P_{1 v f d}$ of variable frequency motor and the estimated consumed power $P_{1 \text { ucd }}$ (Fig. 2). For the considered conveyor it is quantitatively small. If conveyor electric drives operated in the same mode throughout the year the saving $S_{v f d}$ would be equal $667296,07 \mathrm{~kW} \cdot \mathrm{h}$ per year, total for all five motors. 


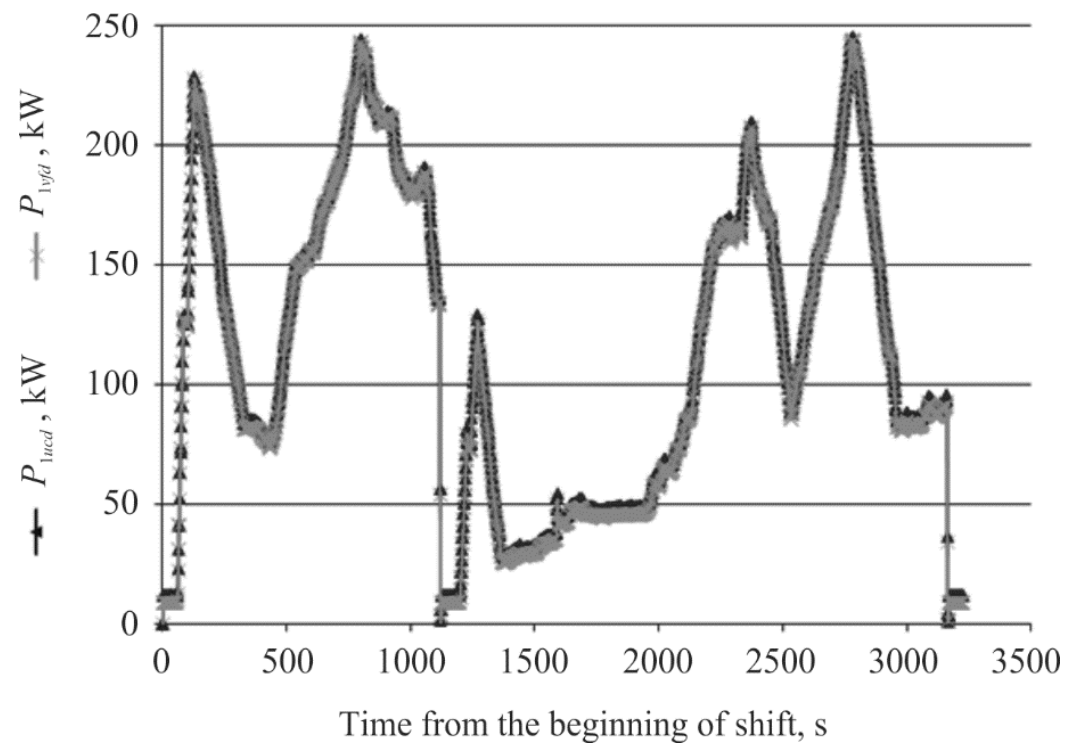

Figure 2. Visualization of saving by the example of the head drive first motor

The second result is the confirmation that the «flux optimization» is actually able to increase the energy efficiency of electric drives of trunk belt conveyor. According the estimation, if conveyor operation mode remained invariant the potential saving $S_{\text {opt }}$ on the first boundary would be equal to $3,51 . .6,11 \mathrm{~kW}$ and on the second one would be equal to $0,79 . .3,75 \mathrm{~kW}$. Additional it should be noted that at low motor load the saving is quite considerable but while the load increases, the saving approaches zero (Fig. 3).

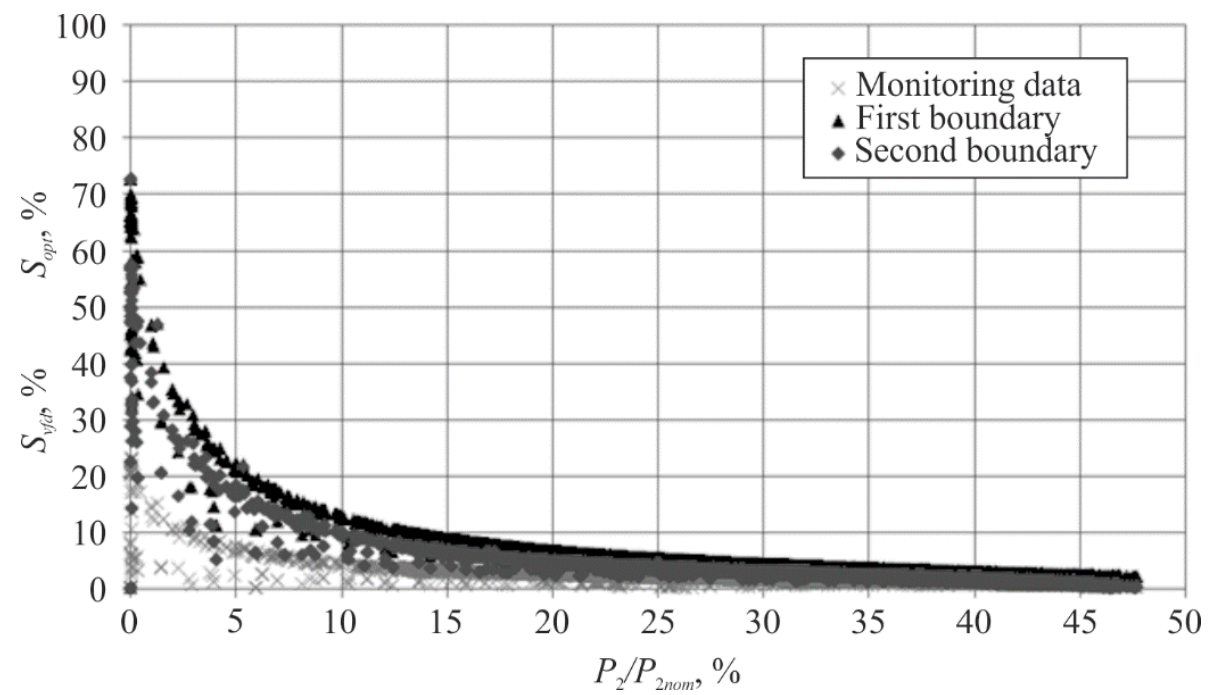

Figure 3. The saving depending on the load

Thus, the study shows that the simple implementation of ACS 800 frequency converters for electric drives of trunk belt conveyor ensures the energy saving from $1,5 \%$ to $10 \%$, and by the «flux optimization» the energy saving can grow up to $40 \%$. 


\section{Conclusion}

According to the experimental results, the following conclusions can be made.

- If the trunk belt conveyor technological schemes does not have constraints, it is necessary to implement the variable frequency drive to controlling of the conveyor speed.

- If capability of speed changing does not exist in conveyor electric drive control system, with the aim of the motor losses optimization the most suitable configuration of control system has to be selected.

- If the frequency converter option like «flux optimization» in ACS 800 are built-in by producers, it should be implemented. If not, the frequency converter control system or the overall automation system should contain no matter which optimization algorithm to search the optimal stator voltage or optimal motor flux.

This work was carried out with the financial support from the State assignments "Science", project "Intelligent Mechatronic Systems", No 3852.

\section{References}

1. B.K Bose, Adjustable speed ac drive (1981)

2. M.P. Kostenko, L.M. Piotrovsky, Electrical Machines (Moscow, 1974)

3. W. Leonard, Control of Electrical Drives (Springer-Verlag, 1985)

4. N.F. Ilinskiy, Y.V. Rozhankovskiy, A.O. Horn, Energy saving technology of power supply of the national economy (Moscow, 1989)

5. O.S. Beshta, Scientific Bulletin NSU, 4, 98 (2012)

6. I.Yu. Krasnov, Methods and tools for energy conservation in industry (Polytechnic University, Tomsk, 2012)

7. M. Zaklika, M. Kollek, C.Tytko, Belt conveyors with adjustable speed, BSS BARTEC, plant "Menden", Germany, CARBO-BARTEC, Poland, mine "ANNA", Poland (1996)

8. I.J. Braslavsky, Z.Sh. Ishmatov, V.N. Polyakov, Energy-saving induction electric drive (manuals Academy, Moscow, 2004)

9. I.Yu. Semykina, Improving energy and resource efficiency of mining machines by means of automatic electric drive, thesis for the degree of Doctor of Technical Sciences, Kemerovo (2013) 